\title{
Development and application of an electrochemical sensor modified with multi-walled carbon nanotubes and graphene oxide for the sensitive and selective detection of tetracycline
}

\author{
Ademar Wong $^{\mathrm{a}, *}$, Mateus Scontri ${ }^{\mathrm{a}}$, Elsa Maria Materon ${ }^{\mathrm{a}}$, Marcos R.V. Lanza ${ }^{\mathrm{b}}$, Maria D.P.T. Sotomayor ${ }^{\mathrm{a}}$ \\ a Department of Analytical Chemistry, Institute of Chemistry, State University of São Paulo (UNESP), 14801-970 Araraquara, SP, Brazil \\ b Instituto de Química de São Carlos, Universidade de São Paulo, P.O. Box 780, CEP 13560-970 São Carlos, SP, Brazil
}

\section{A R T I C L E I N F O}

\section{Article history:}

Received 30 May 2015

Received in revised form 16 September 2015

Accepted 2 October 2015

Available online 9 October 2015

\section{Keywords:}

Electrochemical sensor

Carbon nanotube

Tetracycline

Graphene oxide

Adsorptive stripping differential pulse

voltammetry

\begin{abstract}
A B S T R A C T
In this work, an electrochemical sensor based on a carbon paste electrode modified with a combination of multiwalled carbon nanotubes functionalized with carboxyl groups (MWCNT- $\mathrm{COOH}$ ), together with graphene oxide (GO), was developed for the sensitive and selective determination of tetracycline. Electrochemical sensors were constructed using carbon paste modified with $2.6 \%(w / w)$ of MWCNT-COOH and 3.1\% (w/w) of GO. Under the optimal conditions using adsorptive stripping differential pulse voltammetry (AdSDPV), the sensor showed a linear response for tetracycline concentrations between $2.0 \times 10^{-5}$ and $3.1 \times 10^{-4} \mathrm{~mol} \mathrm{~L}^{-1}$, sensitivity of $1.2 \times 10^{4} \mu \mathrm{A} \mathrm{mol}^{-1}$, and a detection limit of $3.6 \times 10^{-7} \mathrm{~mol} \mathrm{~L}^{-1}$. The incorporation of GO and MWCNT-COOH in the carbon paste improved the sensitivity, selectivity, and stability of the device. The MWCNT-COOH-GO/CPE sensor was successfully applied for the detection of tetracycline in river water, artificial urine, and pharmaceutical samples, without any need for sample pretreatment. The relative standard deviation (RSD) of the electrochemical measurements was less than $6.0 \%(\mathrm{n}=3)$.
\end{abstract}

(c) 2015 Elsevier B.V. All rights reserved.

\section{Introduction}

Tetracycline is one of the antibiotics most commonly used to treat bacterial diseases such as urinary tract infections, chlamydia, and acne. The extensive use of this drug in veterinary medicine has led to its accumulation in food products including meat, milk, honey, and chicken [1]. The impacts of exposure to low levels of antibiotics such as tetracycline include the development of antibiotic-resistant genes, vision problems, teeth discoloration, and allergic symptoms in humans [2,3]. Considering these concerns, it is important to develop analytical methods for the determination of low levels of tetracycline in the environment. Many analytical methods have been reported for tetracycline, such as HPLC [4], spectrophotometry [5], capillary electrophoresis [6], chemiluminescence [7], and electrochemical approaches [8]. With the exception of the electrochemical methods, these techniques require relatively expensive instrumentation, have long times of analysis, and require trained personnel.

Electrochemical sensors and biosensors are widely used in the monitoring of different substances. Carbon, platinum, gold, and silver electrodes are most common, offering the advantages of a wide potential window, low background current, chemical inertness, and low cost [9-11]. The modification of these electrodes with suitable nanostructured materials is fundamental for achieving faster electron transfer

\footnotetext{
* Corresponding author.

E-mail address: ademar.wong@hotmail.com (A. Wong).
}

between the electrode and the analyte, a low detection limit, a wide linear response range, good stability and reproducibility, and increased sensitivity and selectivity of the electrochemical sensor [12-16]. The nanostructured materials studied in this work were multi-walled carbon nanotubes and graphene oxide.

Carbon nanotubes have attracted much attention due to their advantageous mechanical, optical, chemical, and electrical properties. Various applications of carbon nanotubes have been investigated, including their uses in field emitters, quantum wires, batteries, optoelectronic components, ultra-strength engineering fibers, and nanoelectronic devices [17-21]. Recent studies have demonstrated that modification of an electrode with carbon nanotubes can promote high electrocatalytic activity for the detection of captopril, vitamin C, hydrogen peroxide, and some important catecholamine substances such as dopamine, epinephrine, and cytochrome c, among others [18,21-23].

Graphene oxide (GO), a nanomaterial with $\mathrm{sp}^{2}$ hybridization, has extraordinary electrical, physical, and chemical properties. Nanomaterials composed of GO have high surface areas, high specific capacitance, and exhibit electronic transport properties. These features make them attractive for use in energy conversion, field-effect transistors, and batteries. Their applications in electronic device include electrochemical sensors and biosensors for the sensitive determination of analytes including nitrogenous bases (adenine and guanine), pesticides (such as carbofuran), drugs (ascorbic acid, dopamine, and uric acid), diethylstilbestrol, and others [24-28]. Derived from graphene, GO is formed in 
individual layered sheets that contain abundant $\mathrm{C}-\mathrm{O}-\mathrm{C}$ (epoxide), $\mathrm{C}-\mathrm{OH}$, and $\mathrm{COOH}$ functional groups located in the basal planes and at the edges $[29,30]$. Since they have similar compositions, GO and carbon nanotubes exhibit similar physical and chemical properties.

The aim of this work was to develop a sensitive, selective, and stable electrochemical sensor for the determination of tetracycline in pharmaceutical, river water, and artificial urine samples. For this purpose, the working electrode was modified with $\mathrm{GO}$ and MWCNT-COOH, and the experimental conditions were optimized in order to maximize the performance of the sensor.

\section{Materials and methods}

\subsection{Reagents and solutions}

The reagents used in this work were either analytical or HPLC grade. All aqueous solutions were prepared with deionized water $(18 \mathrm{M} \Omega \mathrm{cm}$ at $25^{\circ} \mathrm{C}$ ) obtained from a Milli-Q Direct-0.3 (Millipore) purification system. MWCNT, graphene, mineral oil (Nujol), and graphite powder $(<20 \mu \mathrm{m})$ were acquired from Sigma-Aldrich. $\mathrm{NaOH}, \mathrm{NaH}_{2} \mathrm{PO}_{4} \cdot \mathrm{H}_{2} \mathrm{O}$, TRIS, and PIPES were obtained from Synth (Brazil).

A stock solution of $8.0 \times 10^{-3} \mathrm{~mol} \mathrm{~L}^{-1}$ tetracycline was prepared by dissolving $0.04 \mathrm{~g}$ of the compound in $10.0 \mathrm{~mL}$ of deionized water. The mixture was sonicated for $1 \mathrm{~min}$ to ensure complete dissolution of the tetracycline.

\subsection{Electrochemical measurements}

All voltammetric measurements were performed using a potentiostat (Model $\mu$-Autolab Type III, Autolab/Eco Chemie) fitted with an electrochemical cell containing three electrodes: a commercial $\mathrm{Ag} / \mathrm{AgCl}\left(\mathrm{KCl}_{\text {sat }}\right)$ reference electrode (Analion), a platinum wire as the counter electrode, and a modified carbon paste electrode as the working electrode $(r=$ $1.2 \mathrm{~mm}$ )

\subsection{Construction of the electrochemical sensor}

\subsubsection{Preparation of the modified carbon paste electrode}

The carbon paste electrode (CPE) was prepared using a mixture of $89 \mathrm{mg}$ of graphite powder, $5 \mathrm{mg}$ of MWCNT-COOH, $6 \mathrm{mg}$ of GO, and $1 \mathrm{~mL}$ of $0.1 \mathrm{~mol} \mathrm{~L}^{-1}$ phosphate buffer solution ( $\mathrm{pH} 7.0$ ). Phosphate buffer was used to improve the conductivity of the carbon paste. The material was carefully homogenized for 20 min using a mortar and pestle, and then left to dry at room temperature. Afterwards, $85 \mu \mathrm{L}$ (90 mg) of mineral oil was added to obtain a paste. The paste was then packed into the cavity of the Teflon working electrode $(4 \mathrm{~mm}$ i.d., $1 \mathrm{~mm}$ depth), where a Pt disk was used to provide the electrical contact. The<smiles>CN(C)C1C(O)=C(C(N)=O)C(=O)C2(O)C(O)=C3C(=O)c4c(O)cccc4C(C)(O)C3CC12</smiles>

Tetracycline<smiles>CC1(C)SC2C(NC(=O)C(N)c3ccc(O)cc3)C(=O)N2C1C(=O)O</smiles>

Amoxicillin<smiles>CCCC1CC(C(=O)NC(C(C)Cl)C2OC(SC)C(O)C(O)C2O)N(C)C1</smiles>

Clindamycin<smiles>CCN(CC)CC(=O)Nc1c(C)cccc1C</smiles>

Lidocaine<smiles>NS(=O)(=O)c1cc2c(cc1Cl)NCNS2(=O)=O</smiles>

Hydrochlorothiazide<smiles>CN/C(=C/[N+](=O)[O-])NCCSCC1CC=C(CN(C)C)O1</smiles>

Ranitidine<smiles>CN1C(C(=O)Nc2ccccn2)=C(O)c2ccccc2S1(=O)=O</smiles> 

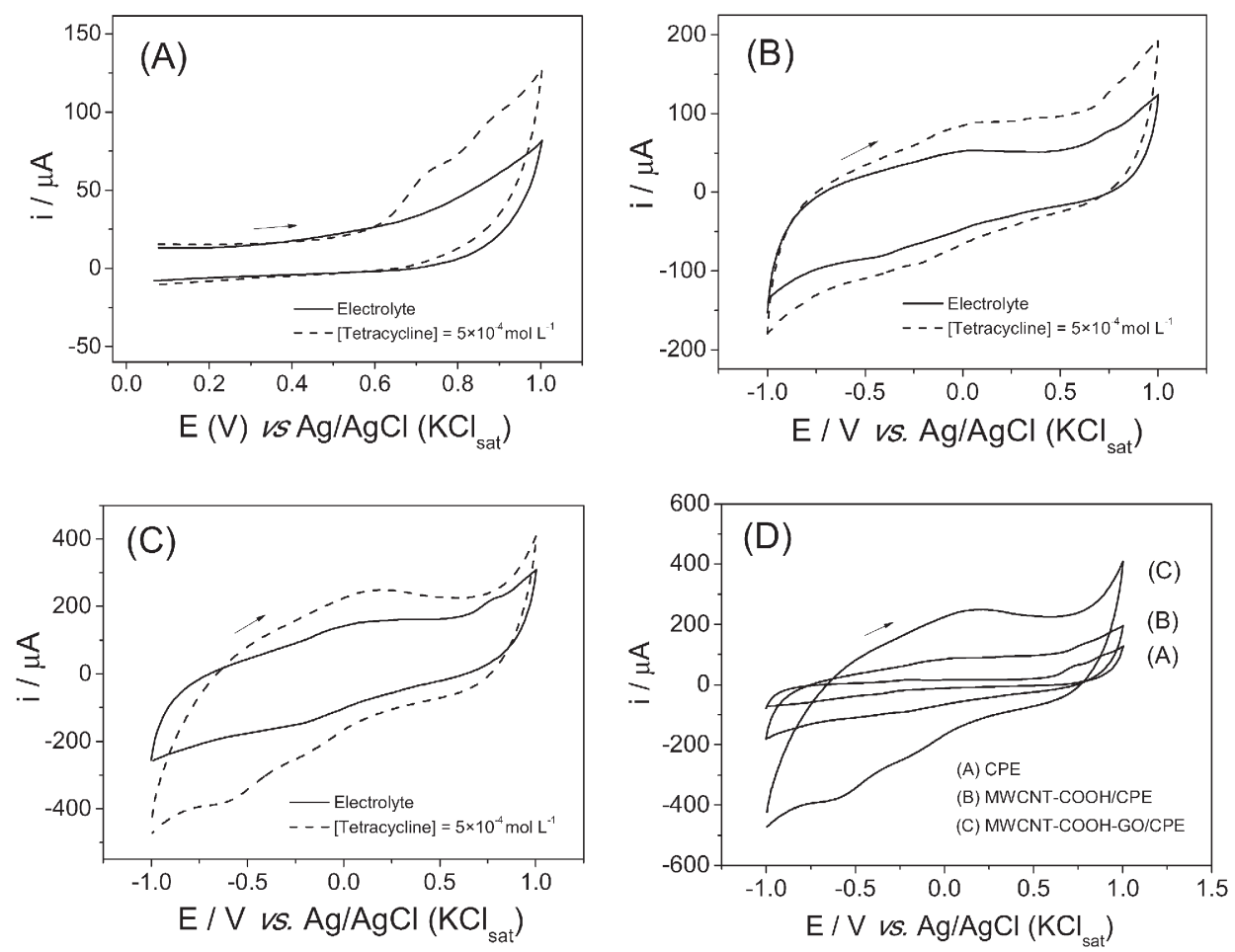

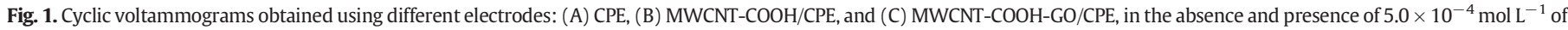

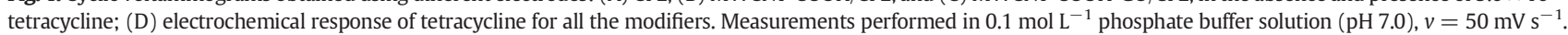

other carbon pastes prepared were as follows: CPE (100 mg of graphite); MWCNT-COOH/CPE (95 mg of graphite and $5 \mathrm{mg}$ of MWCNT$\mathrm{COOH}$ ); and $\mathrm{GO} / \mathrm{CPE}$ (95 $\mathrm{mg}$ of graphite and $5 \mathrm{mg}$ of $\mathrm{GO}$ ). In all cases, the total mass of material used was therefore $100 \mathrm{mg}$. The amounts of phosphate buffer solution and mineral oil used to produce the carbon paste were the same as used for the MWCNT-COOH-GO/CPE.

Functionalization of the MWCNTs consisted of mixing $100 \mathrm{mg}$ of multi-walled carbon nanotubes into a concentrated solution of $1: 3(\mathrm{v} / \mathrm{v})$ $\mathrm{H}_{2} \mathrm{SO}_{4} / \mathrm{HNO}_{3}$. This mixture was stirred for $12 \mathrm{~h}$ [31]. The functionalization of graphene with carboxylic acid groups was performed using a similar procedure, with agitation of $100 \mathrm{mg}$ of graphene in concentrated solution of $1: 1(v / v) \mathrm{H}_{2} \mathrm{SO}_{4} / \mathrm{HNO}_{3}$ for $4 \mathrm{~h}$ at $25^{\circ} \mathrm{C}$. After this step, the suspension of MWCNT-COOH and GO was filtered and carefully washed with deionized water until the $\mathrm{pH}$ was near 7.0. The total volume of acid used in these experiments was $120 \mathrm{ml}$, following the proportions tested (1:1, 1:3, and 3:1

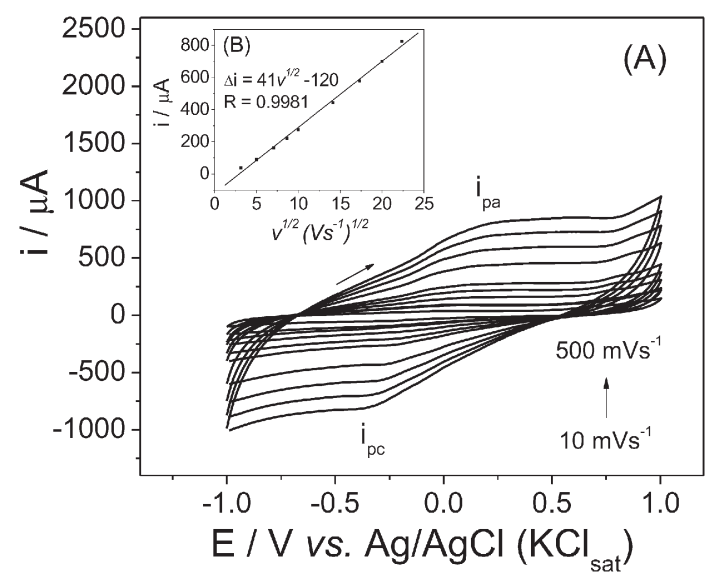

Fig. 2. (A) Typical cyclic voltammograms acquired using different scan rates (10$500 \mathrm{mV} \mathrm{s}^{-1}$ ) and $0.1 \mathrm{~mol} \mathrm{~L}^{-1}$ phosphate buffer solution ( $\mathrm{pH} \mathrm{7.0);} \mathrm{(B)} \mathrm{i}_{\mathrm{pa}} v s . v^{1 / 2}$. [Tetracycline] $=5.0 \times 10^{-4} \mathrm{~mol} \mathrm{~L}^{-1}$. $(v / v))$. The acid ratio used for functionalization of the graphene and carbon nanotubes was based on the best electrochemical performance using $\left[\mathrm{Fe}(\mathrm{CN})_{6}\right]^{4-}$ as a probe.

\subsubsection{Selectivity experiments}

The selectivity of the MWCNT-COOH-GO/CPE sensor was evaluated by analyzing six pharmaceutical formulations, using AdSDPV in the potential range from -0.2 to $1.0 \mathrm{~V}$, at $50 \mathrm{mV} \mathrm{s}^{-1}$. Electrochemical signals were obtained for pharmaceutical formulations containing clindamycin, lidocaine, hydrochlorothiazide, ranitidine, piroxicam, and amoxicillin (Chart 1). The compounds were added to the electrochemical cell to give concentrations of $8.0 \times 10^{-5} \mathrm{~mol} \mathrm{~L}^{-1}$. The following AdSDPV analytical conditions were used: modulation time $=0.1 \mathrm{~s}$, modulation amplitude $=75 \mathrm{mV}, \Delta \mathrm{Es}=4 \mathrm{mV}, \mathrm{E}_{\mathrm{acc}}=0.2 \mathrm{~V}$, and $\mathrm{t}_{\mathrm{acc}}=30 \mathrm{~s}$.

\subsubsection{Application of the MWCNT-COOH-GO/CPE sensor using river water, artificial urine, and pharmaceutical samples}

The MWCNT-COOH-GO/CPE sensor was evaluated using analyses of spiked samples of artificial urine and river water from three sources. The river water samples were collected in the region of Araraquara, in the interior of São Paulo State (Brazil). Artificial urine was synthesized using the following components: $0.73 \mathrm{~g}$ of $\mathrm{NaCl}, 0.40 \mathrm{~g}$ of $\mathrm{KCl}, 0.28 \mathrm{~g}$ of $\mathrm{CaCl}_{2}, 0.56 \mathrm{~g}$ of $\mathrm{Na}_{2} \mathrm{SO}_{4}, 0.35 \mathrm{~g}$ of $\mathrm{KH}_{2} \mathrm{PO}_{4}, 0.25 \mathrm{~g}$ of $\mathrm{NH}_{4} \mathrm{Cl}$, and $6.25 \mathrm{~g}$ of urea. The components were added to a $250 \mathrm{~mL}$ volumetric flask and the volume was completed with deionized water [32].

Table 1

Optimal parameters used in the differential pulse voltammetry analyses.

\begin{tabular}{lcl}
\hline Parameter & Studied range & Optimal value \\
\hline Step potential $(\mathrm{mV})$ & $2-7$ & 4 \\
Modulation amplitude $(\mathrm{mV})$ & $25-100$ & 75 \\
Modulation time $(\mathrm{s})$ & $0.02-1.0$ & 0.5 \\
Accumulation time $(\mathrm{s})$ & $0-60$ & 30 \\
Accumulation potential $(\mathrm{mV})$ & $-400-400$ & 200 \\
\hline
\end{tabular}



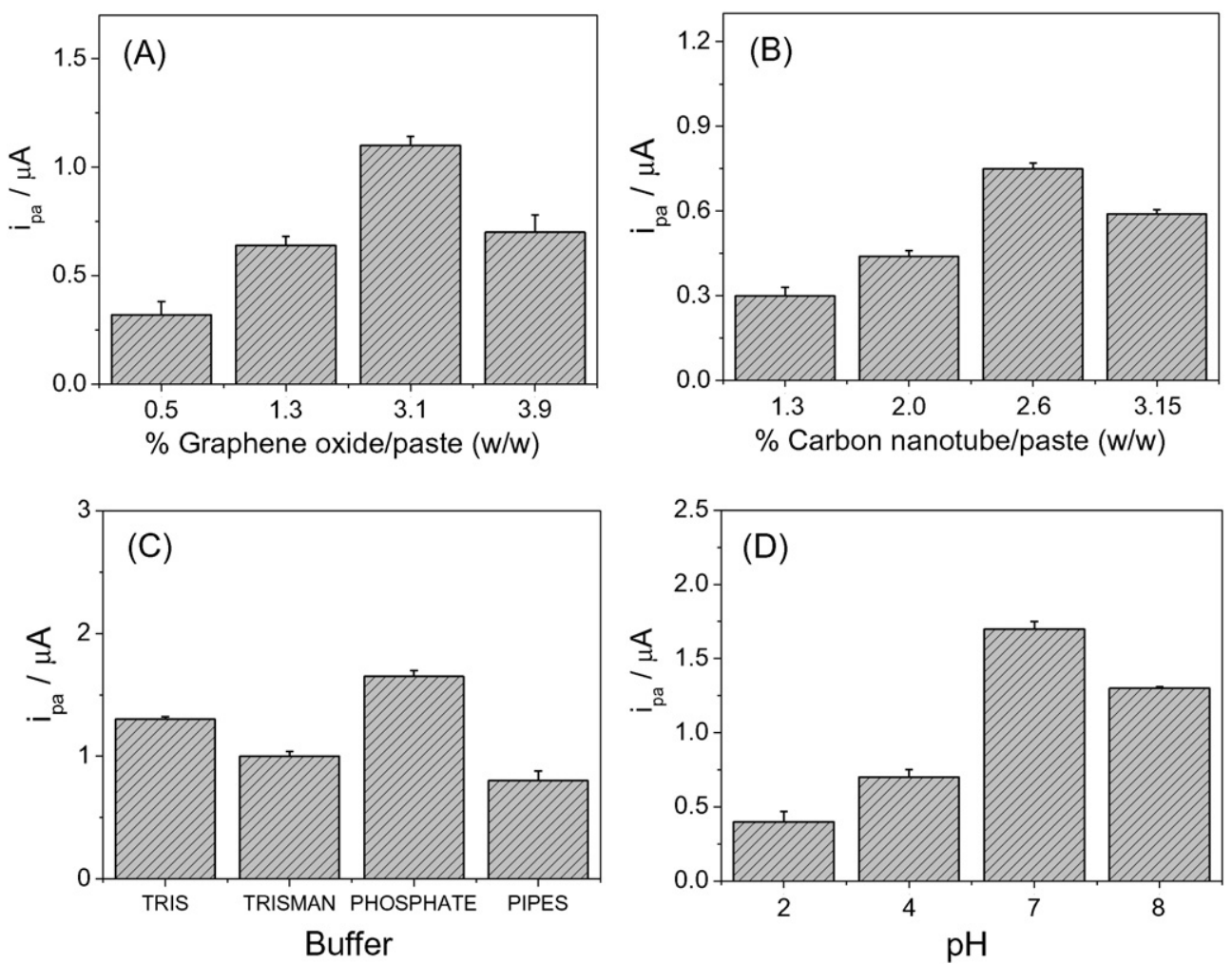

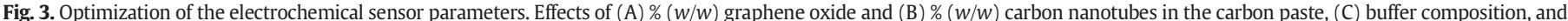

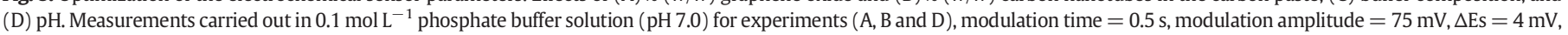
$\mathrm{E}_{\mathrm{acc}}=0.2 \mathrm{~V}$, and $\mathrm{t}_{\mathrm{acc}}=30 \mathrm{~s}$. [Tetracycline] $=1.0 \times 10^{-4} \mathrm{~mol} \mathrm{~L}^{-1}$.
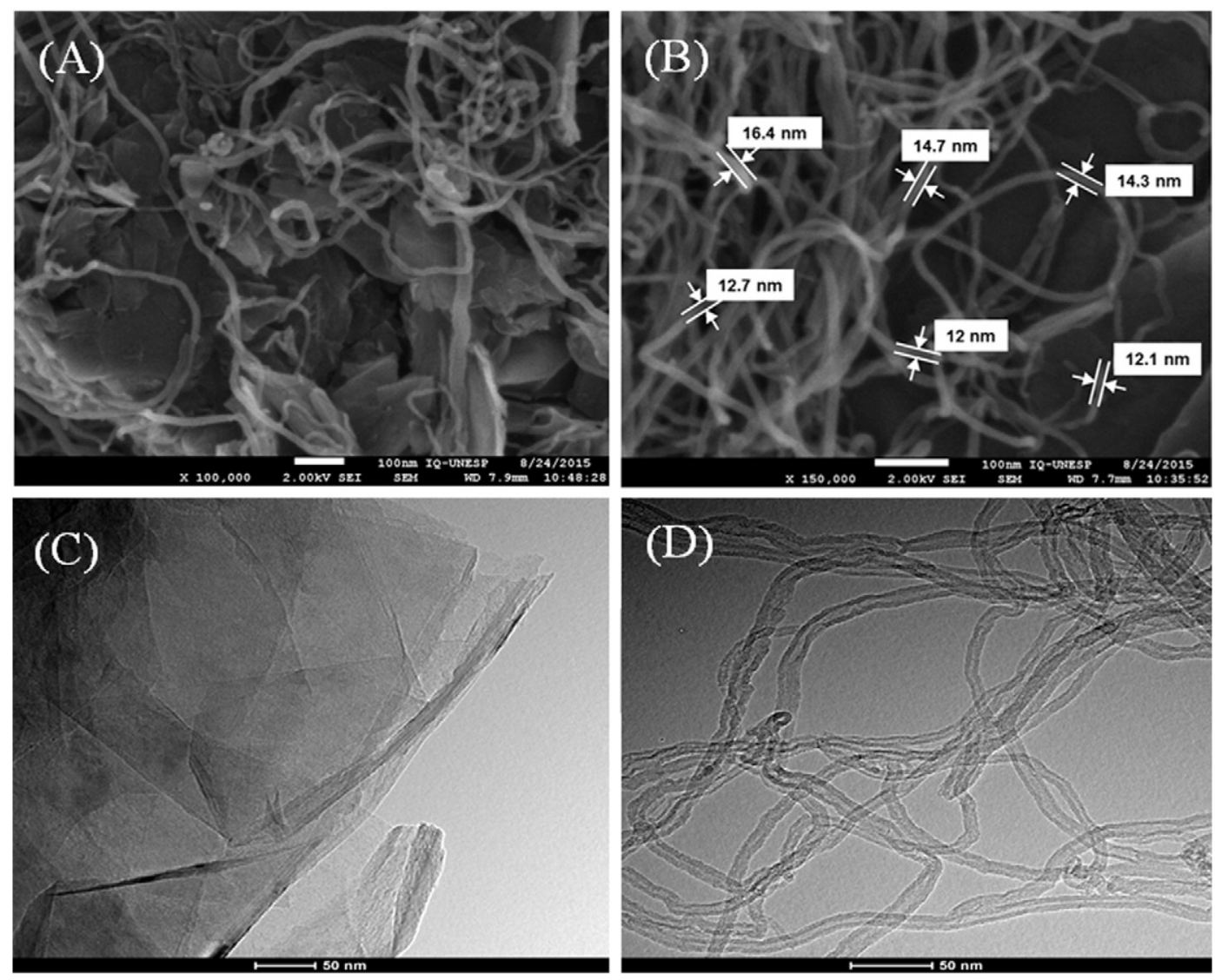

Fig. 4. SEM (A-B) and TEM (C-D) images of graphene oxide and carbon nanotubes. 


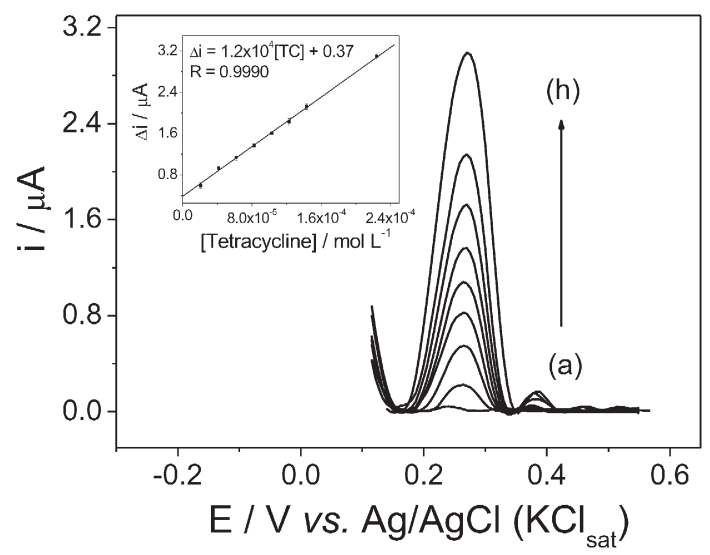

Fig. 5. Response profile using adsorptive stripping differential pulse voltammetry (AdSDPV) for different concentrations of tetracycline. Measurements carried out in $0.1 \mathrm{~mol} \mathrm{~L}^{-1}$ phosphate buffer solution $(\mathrm{pH} 7.0)$, modulation time $=0.5 \mathrm{~s}$, modulation amplitude $=75 \mathrm{mV}, \Delta \mathrm{Es}=4 \mathrm{mV}, \mathrm{E}_{\mathrm{acc}}=0.2 \mathrm{~V}$, and $\mathrm{t}_{\mathrm{acc}}=30 \mathrm{~s}$. [Tetracycline] $=$ (a) $2.0 \times 10^{-5}$, (b) $4.15 \times 10^{-5}$, (c) $6.2 \times 10^{-5}$, (d) $8.3 \times 10^{-5}$, (e) $1.03 \times 10^{-4}$ (f) $1.2 \times 10^{-4}$, (g) $1.7 \times 10^{-4}$, (h) $3.1 \times 10^{-4} \mathrm{~mol} \mathrm{~L}^{-1}$.

All samples were spiked with $4.0 \times 10^{-5} \mathrm{~mol} \mathrm{~L}^{-1}$ tetracycline. The recovery of tetracycline was determined by the standard additions method, with analysis using the MWCNT-COOH-GO/CPE sensor as well as the HPLC technique.

The study of tetracycline in pharmaceutical formulations was carried out using AdSDPV. For the preparation of each sample solution, two tablets were ground and homogenized in a mortar. A suitable amount of triturated sample was then weighed out and dissolved in deionized water, followed by a conventional filtration step to remove insoluble substances present in the solution. The standard additions procedure was used for tetracycline determination, and the results of the electrochemical analyses were compared with those obtained using the HPLC method. Prior to the HPLC analyses, the samples were filtered through $0.45 \mu \mathrm{m}$ membranes.

\subsubsection{Analysis of samples using HPLC}

The chromatographic analyses were performed using a Shimadzu Model 20A liquid chromatograph fitted with a C8 column $(250 \mathrm{~mm} \times$ $4.6 \mathrm{~m}$ ), coupled to an SPD-20A UV/Vis detector, a SIL-20A autosampler, and a DGU-20A5 degasser. The chromatography system was controlled by a microcomputer. The mobile phase was composed of $0.1 \mathrm{~mol} \mathrm{~L}^{-1}$ oxalic acid:methanol:acetonitrile, in a ratio of 68:20:12, at a flow rate of

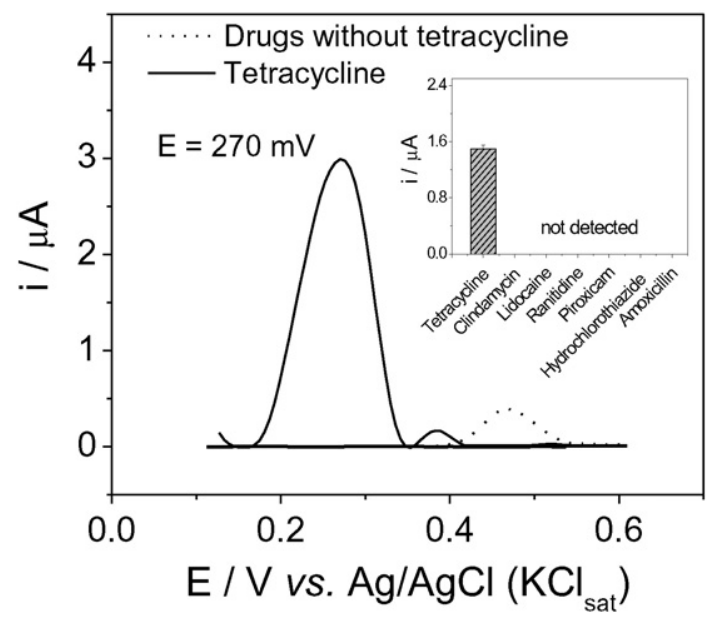

Fig. 6. Study of selectivity using AdSDPV in the presence of six other drugs. Measurements carried out in $0.1 \mathrm{~mol} \mathrm{~L}^{-1}$ phosphate buffer solution ( $\mathrm{pH} \mathrm{7.0)}$, [Tetracycline] $=$ $8.0 \times 10^{-5} \mathrm{~mol} \mathrm{~L}^{-1}$, modulation time $=0.5 \mathrm{~s}$, modulation amplitude $=75 \mathrm{mV}, \Delta \mathrm{Es}=$ $4 \mathrm{mV}, \mathrm{E}_{\mathrm{acc}}=0.2 \mathrm{~V}$, and $\mathrm{t}_{\mathrm{acc}}=30 \mathrm{~s}$.
$1.0 \mathrm{~mL} \mathrm{~min}^{-1}$. The sample injection volume was $10 \mu \mathrm{L}$, and the detector wavelength was $365 \mathrm{~nm}$ [33].

\section{Results}

\subsection{Electrochemical characterization of the MWCNT-COOH-GO/CPE sensor}

First, the behaviors of the electrochemical sensors in the presence of tetracycline were evaluated using cyclic voltammetry (Fig. 1), in order to determine the influence of MWCNT-COOH and GO on the response. Comparison of the cyclic voltammograms obtained for the carbon paste electrode (CPE) using buffer solution and the solution containing tetracycline was made using an anodic peak current of $750 \mathrm{mV} v s$. $\mathrm{Ag} / \mathrm{AgCl}\left(\mathrm{KCl}_{\text {sat }}\right)$ (Fig. 1A). The MWCNT-COOH/CPE voltammogram (Fig. 1B) showed the electrochemical detection of tetracycline at low redox potential, with the appearance of an anodic peak current at a potential of $270 \mathrm{mV} v$ s. $\mathrm{Ag} / \mathrm{AgCl}\left(\mathrm{KCl}_{\text {sat }}\right)$. Inclusion of $\mathrm{GO}$ in the carbon paste composition (MWCNT-COOH-GO/CPE) was then used to increase the magnitude of the electrochemical signal obtained for tetracycline (Fig. 1C). Comparison of the cyclic voltammograms showed that an enhanced response, with high electronic transfer, was obtained using the MWCNT-COOH-GO/CPE electrode, with the presence of an anodic peak current at $0.27 \mathrm{~V}$ and a cathodic peak current at $-0.5 \mathrm{~V} v$ s. $\mathrm{Ag} / \mathrm{AgCl}\left(\mathrm{KCl}_{\text {sat }}\right.$ ) (Fig. 1D) [21,34]. The use of
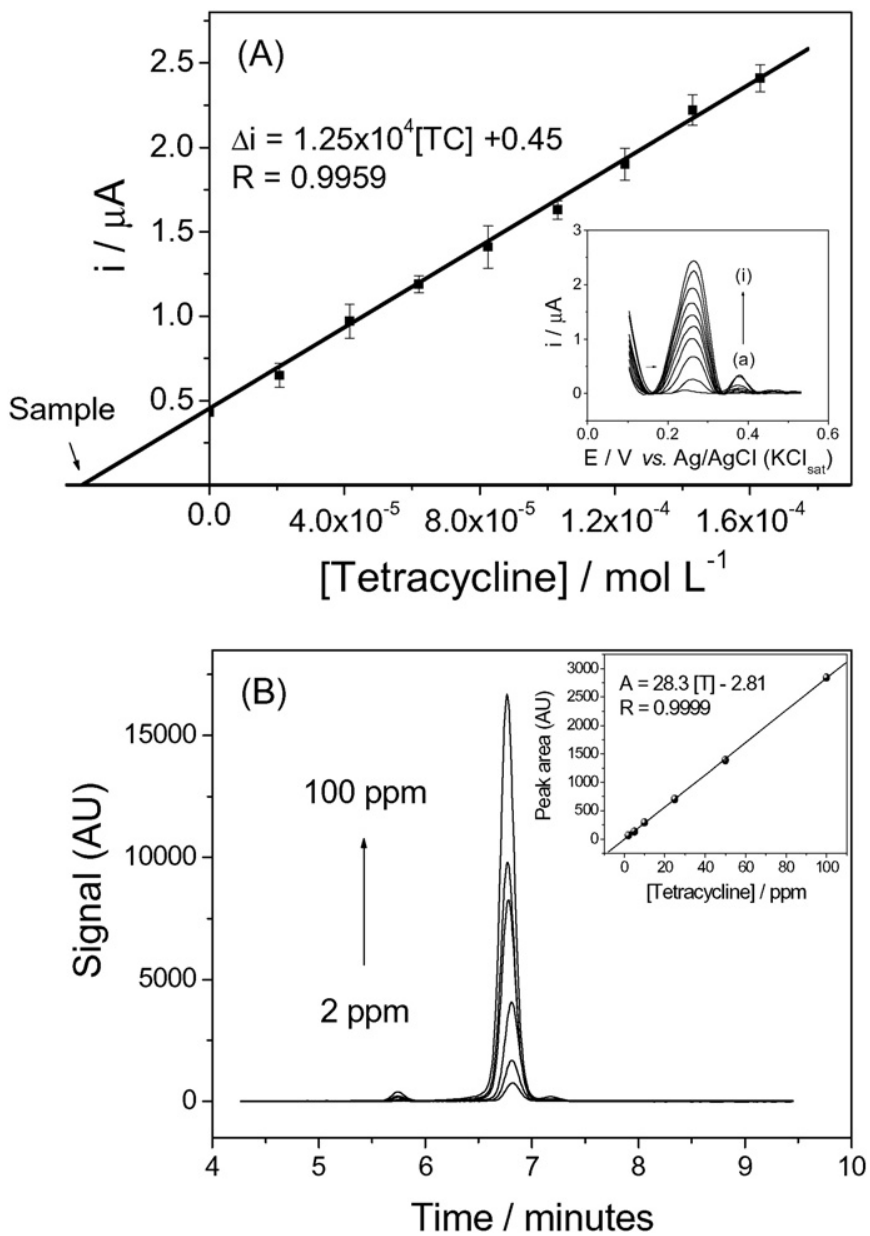

Fig. 7. (A) Typical AdSDPV profiles of the pharmaceutical samples and (insert) analytical curve. Measurements carried out in $0.1 \mathrm{~mol} \mathrm{~L}^{-1}$ phosphate buffer solution ( $\mathrm{pH} 7.0$ ), modulation time $=0.5 \mathrm{~s}$, modulation amplitude $=75 \mathrm{mV}, \Delta \mathrm{Es}=4 \mathrm{mV}, \mathrm{E}_{\mathrm{acc}}=0.2 \mathrm{~V}, \mathrm{t}_{\mathrm{acc}}=$ $30 \mathrm{~s}$, [Tetracycline] = (a) Unknown, (b) $2.1 \times 10^{-5}$, (c) $4.15 \times 10^{-5}$, (d) $6.2 \times 10^{-5}$ (e) $8.3 \times 10^{-5}$, (f) $1.03 \times 10^{-4}$, (g) $1.2 \times 10^{-4}$, (h) $1.4 \times 10^{-4}$, (i) $1.7 \times 10^{-4} \mathrm{~mol} \mathrm{~L}^{-1}$. (B) Calibration curve of tetracycline using high performance liquid chromatography (HPLC). 
Table 2

Comparison of the proposed sensor with other methods described in the literature.

\begin{tabular}{|c|c|c|c|c|}
\hline Electrode & Linear range $\left(\mathrm{mol} \mathrm{L}^{-1}\right)$ & Potential (V) & $\operatorname{LOD}\left(\mathrm{mol} \mathrm{L}^{-1}\right)$ & Reference \\
\hline GCE (Fe/Zn-MMT) ${ }^{\mathrm{a}}$ & $3.0 \times 10^{-5}-5.2 \times 10^{-4}$ & 1.17 & $1.0 \times 10^{-5}$ & [39] \\
\hline $\mathrm{MIP}-\mathrm{Pt} / \mathrm{Ti}^{\mathrm{b}}$ & $2.0 \times 10^{-6}-2.0 \times 10^{-5}$ & 0.8 & $5.3 \times 10^{-8}$ & [40] \\
\hline MWNTsGNPs $^{\mathrm{c}}$ & $2.0 \times 10^{-7}-8.3 \times 10^{-5}$ & 1.1 & $8.3 \times 10^{-8}$ & [41] \\
\hline $\mathrm{GME}^{\mathrm{d}}$ & $2.0 \times 10^{-5}-2.0 \times 10^{-4}$ & 1.5 & $1.8 \times 10^{-7}$ & {$[42]$} \\
\hline GCE $\left(\right.$ IL-MWNT) ${ }^{\mathrm{e}}$ & $1.1 \times 10^{-7}-2.2 \times 10^{-5}$ & 0.54 & $3.0 \times 10^{-8}$ & [43] \\
\hline CPE (GO/MWCNT-COOH) & $2.0 \times 10^{-5}-3.1 \times 10^{-4}$ & 0.27 & $3.6 \times 10^{-7}$ & This work \\
\hline
\end{tabular}

a Iron/zinc cation-exchanged montmorillonite (Fe/Zn-MMT) catalyst on glassy carbon electrode(GCE).

b Micro-nanoPt cluster deposited on titanium sheet $(\mathrm{Pt} / \mathrm{Ti})$.

c Molecularly imprinted polymer modified carbon nanotube-gold nanoparticles electrode.

d Gold modified microelectrode.

e Ionic liquid/carbon nanotubes on glassy carbon electrode.

GO and MWCNT-COOH together resulted in a synergistic effect that increased the electrochemical signal and the stability of the sensor by combining their individual characteristics, such as high electrical conductivity and large specific surface area.

\subsection{Study of the scan rate}

Fig. 2 shows typical cyclic voltammograms acquired at scan rates between 10 and $500 \mathrm{mV} \mathrm{s}^{-1}$. In this range, the change in the anodic current was a linear function of the square root of the scan rate, indicating that the oxidation of tetracycline at a potential of $270 \mathrm{mV}$ was controlled by a diffusion process (Fig. 2).

\subsection{Determination of electroactive surface area}

The electroactive surface areas of the plain carbon paste electrode (CPE), MWCNT-COOH/CPE, and MWCNT-COOH-GO/CPE were estimated using a solution of $4.76 \times 10^{-3} \mathrm{~mol} \mathrm{~L}^{-1}\left[\mathrm{Fe}(\mathrm{CN})_{6}\right]^{4-}$ in $0.1 \mathrm{~mol} \mathrm{~L}^{-1} \mathrm{KCl}$. The calculation employed the Randles-Sevcik equation [35]:

$I_{p}=2.69 \times 10^{5} A D^{1 / 2} n^{3 / 2} v^{1 / 2} C$,

Where $I_{p}$ is the peak current, $D$ is the diffusion coefficient of $\left[\mathrm{Fe}(\mathrm{CN})_{6}\right]^{4-}\left(6.2 \times 10^{-6} \mathrm{~cm}^{2} \mathrm{~s}^{-1}\right), \mathrm{A}$ is the electroactive area $\left(\mathrm{cm}^{2}\right), n$ is the number of electrons, $v$ is the scan rate $\left(\mathrm{V} \mathrm{s}^{-1}\right)$, and $\mathrm{C}$ is the $\left[\mathrm{Fe}(\mathrm{CN})_{6}\right]^{4-}$ concentration $\left(\mathrm{mol} \mathrm{cm}{ }^{-3}\right.$ ). The electroactive surface areas were $6.6 \times 10^{-2}, 0.11$, and $0.18 \mathrm{~cm}^{2}$ for the carbon paste electrode, MWCNT-COOH/CPE, and MWCNT-COOH-GO/CPE, respectively. The surface area obtained with the MWCNT-COOH-GO/CPE was 2.73-fold higher than the value for the plain carbon paste electrode. The results indicated that use of both MWCNT-COOH and GO increased the electroactive area of the electrode, hence increasing the intensity of the peak current.

\subsection{Optimization of AdSDPV parameters}

Optimization of the AdSDPV method considered the following instrumental variables: modulation amplitude, interval time, and

Table 3

Results obtained for the analysis of river water samples collected near the city of Araraquara.

\begin{tabular}{llllr}
\hline $\begin{array}{l}\text { River water } \\
\text { sample }\end{array}$ & \multicolumn{2}{l}{ Tetracycline $\left(\mathrm{mol} \mathrm{L}^{-1}\right)$} & \multicolumn{1}{l}{$\begin{array}{l}\text { Recovery } \\
(\%)\end{array}$} \\
\cline { 2 - 4 } & $\begin{array}{l}\text { Added } \\
(\mathrm{mol} \mathrm{L}\end{array}$ & $\begin{array}{l}\text { Comparative HPLC } \\
\text { method }(\mathrm{RSD})\end{array}$ & $\begin{array}{l}\text { Proposed method } \\
(\mathrm{RSD})\end{array}$ & \\
\hline Jacaré Pepira & $4.0 \times 10^{-5}$ & $3.94 \times 10^{-5}(2.0)$ & $4.16 \times 10^{-5}(5.0)$ & 98.5 \\
Jacaré-Guaçu & $4.0 \times 10^{-5}$ & $4.05 \times 10^{-5}(1.2)$ & $4.24 \times 10^{-5}(4.2)$ & 101.0 \\
Chibarro & $4.0 \times 10^{-5}$ & $3.76 \times 10^{-5}(0.6)$ & $3.68 \times 10^{-5}(2.0)$ & 94.0 \\
\hline
\end{tabular}

$\mathrm{n}=$ triplicate, $\mathrm{RSD}=\sigma / \mu \times 100(\sigma=$ standard deviation of 3 measured concentrations; $\mu$ $=$ average of 3 measured concentrations). modulation time (Table 1). Selection of the best conditions was based on the highest anodic peak currents obtained using AdSDPV. Figs. $3 \mathrm{~A}$ and $3 \mathrm{~B}$ show the influence of the amounts of MWCNT$\mathrm{COOH}$ and $\mathrm{GO}$ incorporated in the carbon paste. The effects of buffer type, buffer concentration, and $\mathrm{pH}$ on the anodic peak current $\left(\mathrm{i}_{\mathrm{pa}}\right)$ of tetracycline were also studied (Figs. 3C and 3D). The best response was obtained using 3.1\% $(w / w)$ GO and 2.6\% ( $w / w)$ MWCNT-COOH in the carbon paste, and $0.1 \mathrm{~mol} \mathrm{~L}^{-1}$ phosphate buffer solution ( $\mathrm{pH} \mathrm{7.0)}$ ).

The morphological characteristics of the carbon paste sensor modified with MWCNT-COOH and GO were evaluated using images acquired using a JEOL JSM 7500F scanning electron microscope. As shown in Fig. 4A, the GO consisted of thin sheets of different sizes, while the MWCNT-COOH was composed of cylindrical tubes with diameters of 12-17 nm (Fig. 4B). Both materials were deposited onto graphite, which was arranged in large blocks. Figs. 4C and 4D show detailed characteristics of these materials in TEM images acquired using a TECNAI G2 microscope. GO was present in the form of transparent and wrinkled sheets, which provided a high surface area on the electrode, while the inner and outer walls of the cylindrical tubes of MWCNT-COOH had diameters similar to those obtained using SEM (Fig. 4B) [36,37].

The response profile obtained using AdSDPV (modulation time $=0.5 \mathrm{~s}$, modulation amplitude $=75 \mathrm{mV}, \Delta \mathrm{Es}=4 \mathrm{mV}$, accumulation potential $\left(\mathrm{E}_{\mathrm{acc}}\right)=0.2 \mathrm{~V}$, and accumulation time $\left.\left(\mathrm{t}_{\mathrm{acc}}\right)=30 \mathrm{~s}\right)$ showed a linear correlation coefficient of 0.9990 for determination of tetracycline at concentrations between $2.0 \times 10^{-5}$ and $3.1 \times 10^{-4} \mathrm{~mol} \mathrm{~L}^{-1}$. The sensitivity was $1.2 \times 10^{4} \mu \mathrm{A} \mathrm{L} \mathrm{mol}{ }^{-1}$, and the detection limit was $3.6 \times 10^{-7} \mathrm{~mol} \mathrm{~L}^{-1}(3 \times \mathrm{SD} / \mathrm{m}$, where SD is the standard deviation for the blank solution $(n=10)$ and $m$ is the slope of the analytical curve) (Fig. 5) [38].

The reproducibility of the sensor response was determined from five analytical curves obtained using AdSDPV, for which the relative standard deviation (RSD) was 3.1\%.

A comparison was made of these results with others reported in the literature (Table 2). It can be seen that the MWCNT-COOH-GO/ CPE sensor provided a similar detection limit, with additional advantages that make this sensor more attractive than the other methods, such as lower detection potential, the ability to perform numerous analyses by renewing the electrode surface using simple

Table 4

Results obtained for the analysis of artificial urine samples with the electrochemical sensor and HPLC.

\begin{tabular}{lllll}
\hline $\begin{array}{l}\text { Artificial urine } \\
\text { sample }\end{array}$ & \multicolumn{2}{l}{ Tetracycline $\left(\mathrm{mol} \mathrm{L}^{-1}\right)$} & $\begin{array}{l}\text { Recovery } \\
\text { (\%) }\end{array}$ \\
\cline { 2 - 4 } & $\begin{array}{l}\text { Added }(\mathrm{mol} \\
\left.\mathrm{L}^{-1}\right)\end{array}$ & $\begin{array}{l}\text { Official HPLC } \\
\text { method (RSD) }\end{array}$ & $\begin{array}{l}\text { Proposed method } \\
\text { (RSD) }\end{array}$ & \\
\hline $\mathrm{n}^{\circ} 1$ & $4.0 \times 10^{-5}$ & $3.9 \times 10^{-5}(1.5)$ & $3.68 \times 10^{-5}(5.5)$ & 92.0 \\
$\mathrm{n}^{\circ} 2$ & $4.0 \times 10^{-5}$ & $4.05 \times 10^{-5}(1.0)$ & $3.85 \times 10^{-5}(5.0)$ & 96.2 \\
\hline
\end{tabular}

$\mathrm{n}=$ triplicate, $\mathrm{RSD}=\sigma / \mu \times 100(\sigma=$ standard deviation of 3 measured concentrations; $\mu=$ average of 3 measured concentrations). 


\section{Table 5}

Results obtained with the proposed sensor and the comparative method (HPLC) in the analysis of pharmaceutical formulations containing tetracycline.

\begin{tabular}{lllll}
\hline $\begin{array}{l}\text { Pharmaceutical } \\
\text { formulation }\end{array}$ & \begin{tabular}{l} 
Tetracycline $\left(\mathrm{mg} \mathrm{tablet}^{-1}\right)$ \\
Nominal \\
\cline { 2 - 4 }
\end{tabular} & $\begin{array}{l}\text { Official HPLC } \\
\text { method (RSD) }\end{array}$ & $\begin{array}{l}\text { Proposed } \\
\text { method (RSD) }\end{array}$ & \\
\hline $\mathrm{n}^{\circ} 1$ & 500 & $485(2.0)$ & $467(1.3)$ & 93.4 \\
$\mathrm{n}^{\circ} 2$ & 500 & $505(0.8)$ & $510(2.3)$ & 102.0 \\
$\mathrm{n}^{\circ} 3$ & 500 & $510(0.6)$ & $532(4.2)$ & 106.0 \\
\hline
\end{tabular}

$\mathrm{n}=$ triplicate, $\mathrm{RSD}=\sigma / \mu \times 100(\sigma=$ standard deviation of 3 measured values; $\mu=$ average of 3 measured values).

polishing, high repeatability, a stable analytical response for 15 days, and low cost. The sensor showed a much lower detection potential of $270 \mathrm{mV}$ vs. $\mathrm{Ag} / \mathrm{AgCl}$, especially compared to the CPE method, where the electrochemical detection occurred at a potential of $750 \mathrm{mV}$. The lower potential increased the selectivity of the proposed sensor in the determination of tetracycline.

The selectivity of the MWCNT-COOH-GO/CPE sensor towards tetracycline was evaluated by observation of its response to six pharmaceutical formulations soluble in the water. Fig. 6 shows that among all the potentially electroactive compounds, only tetracycline induced an electrochemical response, with an anodic peak current $\left(\mathrm{I}_{\mathrm{pa}}\right)$ at a potential of $270 \mathrm{mV} v$ s. $\mathrm{Ag} / \mathrm{AgCl}\left(\mathrm{KCl}_{\mathrm{sat}}\right)$. This demonstrated the high selectivity of the MWCNT-COOH-GO/CPE sensor in the detection of tetracycline. The literature reports many analytes that exhibit electrochemical activity at relatively high potentials (above $700 \mathrm{mV}$ ), which further supports the use of the MWCNT-COOH-GO/CPE sensor for the highly selective electrochemical determination of tetracycline [39,44-46].

\subsection{Application of the MWCNT-COOH-GO/CPE sensor using river water, ar- tificial urine, and pharmaceutical samples}

The performance of the MWCNT-COOH-GO/CPE sensor was evaluated using analyses of river water and artificial urine samples fortified with tetracycline. The results showed recoveries in the range from 92 to $101 \%$, demonstrating an absence of matrix effects. The RSD values obtained in these analyses were $\leq 5.5 \%(n=3)$, indicating the high reproducibility and reliability of the MWCNT-COOH-GO/CPE sensor (Tables 3 and 4).

Table 5 shows the results obtained for the analyses of the pharmaceutical samples using the electrochemical and HPLC techniques. No significant differences were found between the two methods, from which it could be concluded that the proposed device offers an efficient and highly reliable method for the determination of tetracycline in this type of matrix. The RSD values obtained for three different concentrations, using the standard additions procedure, were lower than $4.2 \%$, indicating good precision of the method. Fig. 7A shows the determination of tetracycline in pharmaceutical samples using the proposed sensor and the standard additions procedure. Fig. 7B shows the tetracycline calibration curve obtained using the HPLC method, which had an analyte retention time of $6.8 \mathrm{~min}$ and an analysis time of about $10 \mathrm{~min}$ per sample. In comparison, use of the proposed sensor enabled seven analytical measurements to be made in around $5 \mathrm{~min}$, clearly demonstrating the advantages of this alternative methodology for the monitoring of tetracycline.

An assessment was made of possible interferences in the analytical signal caused by the presence of substances commonly found in commercial pharmaceutical formulations. The interferents studied were magnesium stearate, sodium lauryl sulfate, and talc, using interferent:tetracycline ratios of $1: 1(w / w)$. In all cases, only tetracycline showed a measurable electrochemical response at a potential of $270 \mathrm{mV}$.

\section{Conclusions}

The construction of an electrochemical sensor by modification of a carbon paste electrode with a combination of MWCNT-COOH and GO enabled the sensitive and selective determination of tetracycline. The proposed method presented a detection limit of $3.6 \times 10^{-7} \mathrm{~mol} \mathrm{~L}^{-1}$ and a relative standard deviation of $3.1 \%(n=5)$. In recovery tests using river water, artificial urine, and pharmaceutical samples, there were no matrix effects and the measured values were similar to those obtained by an HPLC method. In addition, the sensor showed advantages including simple sample preparation, rapid response, long electrode lifetime, low detection limit, low analysis potential, good repeatability, and low cost, when compared to other detection methods reported in the literature.

\section{Acknowledgments}

The authors gratefully acknowledge financial support from FAPESP (Procs. 2011/003008-7 and 2014/25264-3).

\section{References}

[1] H. Wang, H. Zhao, X. Quan, S. Chen, Electrochemical determination of tetracycline using molecularly imprinted polymer modified carbon nanotube-gold nanoparticles electrode, Electroanalysis 23 (2011) 1863-1869.

[2] D. Chen, D. Yao, C. Xie, D. Liu, Development of an aptasensor for electrochemical detection of tetracycline, Food Control 42 (2014) 109-115.

[3] Y.-J. Kim, Y.S. Kim, J.H. Niazi, M.B. Gu, Electrochemical aptasensor for tetracycline detection, Bioprocess Biosyst. Eng. 33 (2010) 31-37.

[4] K. Ng, S.W. Linder, HPLC separation of tetracycline analogues: comparison study of laser-based polarimetric detection with UV detection, J. Chromatogr. Sci. 41 (2003) 460-466.

[5] A.J. Abdulghani, H.H. Jasim, A.S. Hassan, Determination of tetracycline in pharmaceutical preparation by molecular and atomic absorption spectrophotometry and high performance liquid chromatography via complex formation with $\mathrm{Au}(\mathrm{III})$ and $\mathrm{Hg}$ (II) ions in solutions, Int. Anal. Chem. 2013 (2013) 1-11.

[6] G. Mu, H. Liu, L. Xu, L. Tian, F. Luan, Matrix solid-phase dispersion extraction and capillary electrophoresis determination of tetracycline residues in milk, Food Anal. Methods 5 (2012) 148-153.

[7] X. Chen, L. Zhao, X. Tian, S. Lian, Z. Huang, X. Chen, A novel electrochemiluminescence tetracyclines sensor based on $\mathrm{aRu}(\mathrm{bpy})_{3}^{2+}{ }^{+}$-doped silicananoparticles/Nafion film modified electrode, Talanta 129 (2014) 26-31.

[8] S. Sattayasamitsathit, P. Thavarungkul, P. Kanatharanaa, Bismuth film electrode for analysis of tetracycline in flow injection system, Electroanalysis 19 (2007) 502-505.

[9] A. Wong, M.D.P.T. Sotomayor, Determination of carbofuran and diuron in FIA system using electrochemical sensor modified with organometallic complexes and graphene oxide, J. Electroanal. Chem. 731 (2014) 163-171.

[10] M.D.P.T. Sotomayor, A.A. Tanaka, R.S. Freire, L.T. Kubota, Amperometric Sensors Based on Biomimetic Catalysts, in: C.A. Grimes, E.C. Dickey, M.V. Pishko (Eds.), Encyclopedia of Sensors, American Scientific Publishers, California, 2006

[11] A. Wong, M.D.P.T. Sotomayor, Biomimetic sensor based on 5,10,15,20tetrakis(pentafluorophenyl)-21 H,23 H-porphyrin iron (III) chloride and MWCNT for selective detection of 2,4-D, Sens. Actuators, B 181 (2013) 332-339.

[12] F.C. Moraes, L.H. Mascaro, S.A.S. Machado, C.M.A Brett, direct electrochemical determination of glyphosate at copper phthalocyanine/multiwalled carbon nanotube film electrodes, Electroanalysis 22 (2010) 1586-1591.

[13] H. Beitollah, M. Goodarzian, M.A. Khalilzadeh, H. Karimi-Maleh, M. Hassanzadeh, M. Tajbakhsh, Electrochemical behaviors and determination of carbidopa on carbon nanotubes ionic liquid paste electrode, J. Mol. Liq. 173 (2012) 137-143.

[14] A. Wong, L.D. Marestoni, M.D.P.T. Sotomayor, Monitoring of diclofenac with biomimetic sensor in batch and FIA systems, J. Braz. Chem. Soc. 25 (2014) 1-9.

[15] M. Shamsipur, M. Najafia, M.-R.M. Hosseini, Highly improved electrooxidation of glucose at a nickel (II) oxide/multi-walled carbon nanotube modified glassy carbon electrode, Bioelectrochem 77 (2010) 120-124.

[16] A. Mokhtar, H. Karimi-maleh, A.A. Ensafi, H. Beitollahi, Application of modified multiwall carbon nanotubes paste electrode for simultaneous voltammetric determination of morphine and diclofenac in biological and pharmaceutical samples, Sens. Actuators, B 169 (2012) 96-105.

[17] C.B. Jacobs, M.J. Peairs, B.J. Venton, Review: carbon nanotube based electrochemical sensors for biomolecules, Anal. Chim. Acta 662 (2010) 105-127.

[18] S. Gheibi, H. Karimi-Maleh, M.A. Khalilzadeh, H. Bagheri, A new voltammetric sensor for electrocatalytic determination of vitamin $C$ in fruit juices and fresh vegetable juice using modified multi-wall carbon nanotubes paste electrode, J. Food Sci. Technol. 52 (2015) 276-284.

[19] A.J.S. Ahammad, J.-J. Lee, M.A. Rahman, Electrochemical sensors based on carbon nanotubes, Sensors 9 (2009) 2289-2319.

[20] U. Yogeswaran, S. Thiagarajan, S.-M. Chen, Recent updates of DNA incorporated in carbon nanotubes and nanoparticles for electrochemical sensors and biosensors, Sensors 8 (2008) 7191-7212. 
[21] X.-X. Yan, D.-W. Pang, Z.-X. Lu, J.-O. Lü, H. Tong, Electrochemical behavior of L-dopa at single-wall carbon nanotube-modified glassy carbon electrodes, J. Electroanal Chem. 569 (2004) 47-52.

[22] M. Siswana, K.I. Ozoemena, T. Nyokong, Electrocatalytic detection of amitrole on the multi-walled carbon nanotube-iron (II) tetra-aminophthalocyanine platform, Sensors 8 (2008) 5096-5105.

[23] B. Rezaei, S. Damiri, Voltammetric behavior of multi-walled carbon nanotubes modified electrode-hexacyanoferrate (II) electrocatalyst system as a sensor for determination of captopril, Sensors Actuators B 134 (2008) 324-331

[24] L.-M. Lu, X.-L. Qiu, X.-B. Zhang, G.-L. Shen, W. Tan, R.-Q. Yu, Supramolecular assembly of enzyme on functionalized graphene for electrochemical biosensing, Biosens. Bioelectron. 45 (2013) 102-107.

[25] Y.-S. Gao, J.K. Xu, L.-M. Lun, L.-P. Wu, K.-X. Zhang, T. Nie, X.-F. Zhu, Y. Wu, Overoxidized polypyrrole/graphene nanocomposite with good electrochemical performance as novel electrode material for the detection of adenine and guanine, Biosens. Bioelectron. 62 (2014) 261-267.

[26] X. Zhu, L. Lu, X. Duan, K. Zhanga, J. Xu, D. Hu, H. Sun, L. Dong, Y. Gao, Y. Wu, Efficient synthesis of graphene-multiwalled carbon nanotubes nanocomposite and its application in electrochemical sensing of diethylstilbestrol, J. Electroanal. Chem. 731 (2014) 84-92.

[27] C. Wang, J. Du, H. Wang, C. Zou, F. Kiang, P. Yang, Y. Du, A facile electrochemica sensor based on reduced graphene oxide and Au nanoplates modified glassy carbon electrode for simultaneous detection of ascorbic acid, dopamine and uric acid, Sensors Actuators B 204 (2014) 302-309.

[28] A. Wong, M.D.P.T. Sotomayor, Determination of carbofuran and diuron in FIA system using electrochemical sensor modified with organometallic complexes and graphene oxide, J. Electroanal. Chem. 731 (2014) 163-171.

[29] D. Chen, H. Feng, J. Li, Graphene oxide: preparation, functionalization, and electrochemical applications, Chem. Rev. 112 (2012) 6027-6053.

[30] S. Roy, N. Soin, R. Bajpai, D.S. Misra, J.A. McLaughlinb, S.S. Roy, Graphene oxide for electrochemical sensing applications, J. Mater. Chem. 21 (2011) 14725-14731.

[31] A.G. Osorio, I.C.L. Silveira, V.L. Bueno, C.P. Bergmann, $\mathrm{H}_{2} \mathrm{SO}_{4} / \mathrm{HNO}_{3} / \mathrm{HCl}$ functionalization and its effect on dispersion of carbon nanotubes in aqueous media, Appl. Surf. Sci. 255 (2008) 2485-2489.

[32] P.B. Deroco, F.C. Vicentini, G.G. Oliveira, R.C. Rocha-Filho, O. Fatibello-Filho, Squarewave voltammetric determination of hydroxychloroquine in pharmaceutical and synthetic urine samples using a cathodically pretreated boron-doped diamond electrode, J. Electroanal. Chem. 719 (2014) 19-23.
[33] A.R. Shalabya, N.A. Salamab, S.H. Abou-Rayab, W.H. Emama, F.M. Mehayaa, Validation of HPLC method for determination of tetracycline residues in chicken meat and liver, Food Chem. 124 (2011) 1660-1666.

[34] A. Merkoc, M. Pumera, X. Llopis, B. Perez, M. Valle, S. Alegret, New materials for electrochemical sensing VI: carbon nanotubes, Trends Anal. Chem. 24 (2005) 826-838.

[35] C.P. Andrieux, J.M. Saviant, Electron transfer through redox polymer films, J. Electroanal. Chem. 111 (1980) 377-381.

[36] X. Kang, J. Wang, H. Wu, H. Liu, I.A. Aksay, Y. L., A graphene-based electrochemical sensor for sensitive detection of paracetamol, Talanta 81 (2010) 754-759.

[37] C. Branca, F. Frusteri, V. Magazu, A. Mangione, Characterization of carbon nanotubes by TEM and infrared spectroscopy, J. Phys. Chem. B 108 (2004) 3469-3473.

[38] F.C. Vicentinia, B.C. Janegitza, C.M.A. Brett, O. Fatibello-Filho, Tyrosinase biosensor based on a glassy carbon electrode modified with multi-walled carbon nanotubes and1-butyl-3-methylimidazolium chloride within a dihexadecylphosphate film, Sensors Actuators B Chem. 188 (2013) 1101-1108.

[39] T. Gan, Z. Shi, J. Sun, Y. Liu, Simple and novel electrochemical sensor for the determination of tetracycline based on iron/zinc cations-exchanged montmorillonite catalyst, Talanta 121 (2014) 187-193.

[40] H. Zhao, H. Wanga, X. Quana, F. Tana, Amperometric sensor for tetracycline determination based on molecularly imprinted technique, Procedia Environ. Sci. 18 (2013) 249-257.

[41] H. Wang, H. Zhao, X. Quan, S. Chen, Electrochemical determination of tetracycline using molecularly imprinted polymer modified carbon nanotube-gold nanoparticles electrode, Electroanal 23 (2011) 1863-1869.

[42] H. Wang, H. Zhao, X. Quan, Gold modified microelectrode for direct tetracycline detection, Front. Environ. Sci. Eng. 6 (2012) 313-319.

[43] G. Guo, F. Zhao, F. Xiao, B. Zeng, Voltammetric determination of tetracycline by using multi-wall carbon nanotube - ionic liquid film coated glassy carbon electrode, Int. J. Electrochem. Sci. 4 (2009) 1365-1372.

[44] A.A.J. Torriero, C.E. Tonn, L. Sereno, J. Raba, Electrooxidation mechanism of non-steroidal anti-inflammatory drug piroxicam at glassy carbon electrode, J. Electroanal. Chem. 588 (2006) 218-225.

[45] G. Yangab, F. Zhao, A novel electrochemical sensor for the determination of lidocaine based on surface-imprinting on porous three-dimensional film, J. Mater. Chem. C 2 (2014) 10201-10208.

[46] L. Svorc, D.M. Stankovic, K. Kalcher, Boron-doped diamond electrochemical sensor for sensitive determination of nicotine in tobacco products and anti-smoking pharmaceuticals, Diam. Relat. Mater. 42 (2014) 1-7. 